\title{
Relationship of food consumption with eating behaviours of professional women
}

\author{
AATMA SINGH, KIRAN BAINS AND HARPREET KAUR
}

Received: 22.05.2017; Revised: 20.10.2017; Accepted: 03.11.2017

See end of the paper for authors' affiliations

\section{KIRAN BAINS}

Department of Food and Nutrition, Punjab Agricultural University,

LUDHIANA (PUNJAB) INDIA

Email : kiranbains68@ hotmail.

com
ABSTRACT : A cross-sectional study was conducted to study the relationship of food consumption frequency on eating behaviours (cognitive dietary restraint, uncontrolled eating and emotional eating) among women. Food consumption frequency score and eating behaviours were determined among one hundred professional women engaged in teaching (30-59 years old) across five colleges of Jalandhar city of Punjab. The older age groups i.e. 40 to 49 and 50 to 59 years reported significantly $(\mathrm{p} \leq 0.05)$ high scores of disinhibition whereas, young age group (30-39 years) reported high scores for cognitive dietary restraint. Uncontrolled eating had a positive and significant $(\mathrm{p} \leq 0.05,0.01)$ correlation with consumption frequency of traditional snacks, western snacks, egg, meat and fish and eating out among the 30-39 years age group. While in the subjects aged 40-49 years, uncontrolled eating was significantly correlated ( $\mathrm{p} \leq$ $0.10,0.05$ ) with higher consumption frequency of snacks while emotional eating was significantly $(\mathrm{p} \leq 0.10,0.05)$ correlated with the higher consumption frequency of snacks, egg, meat and fish as well as frequency of eating out. Cognitive restraint was significantly $(\mathrm{p} \leq 0.10)$ correlated with lesser consumption frequency of snacks. In 50-59 years group, higher consumption frequency of snacks was significantly $(\mathrm{p} \leq 0.10)$ correlated with uncontrolled eating and emotional eating while higher frequency of eating out was significantly $(\mathrm{p} \leq 0.05)$ related to emotional eating. The study concluded that eating behaviours majorly influenced the food choices of adult professional women thus, may predispose them to subsequent weight gain and development of obesity.

KEY WORDS: Cognitive dietary restraint, Uncontrolled eating, Emotional eating, Food consumption frequency, Eating out

- HOW TO CITE THIS PAPER : Singh, Aatma, Bains, Kiran and Kaur, Harpreet (2017). Relationship of food consumption with eating behaviours of professional women. Asian J. Home Sci., 12 (2) : 515-521, DOI: 10.15740/HAS/AJHS/12.2/515-521. 